\title{
IPI Score 4-5
}

National Cancer Institute

\section{Source}

National Cancer Institute. IPI Score 4-5. NCI Thesaurus. Code C161650.

A score of 4 or 5 on the International Prognostic Index indicating that an individual has a high risk of prog ression of non-Hodgkin lymphoma and a 5 year survival of $32 \%$. 